\title{
Editorial \\ Precipitation Measurement Instruments: Calibration, Accuracy and Performance
}

\author{
Luca G. Lanza ${ }^{1,2, *(1)}$ and Arianna Cauteruccio ${ }^{1,2}$ (1) \\ 1 Department of Civil, Chemical and Environmental Engineering, University of Genova, 16145 Genova, Italy; \\ arianna.cauteruccio@edu.unige.it \\ 2 WMO/CIMO Lead Centre "B. Castelli" on Precipitation Intensity, 16145 Genova, Italy \\ * Correspondence: luca.lanza@unige.it
}

check for updates

Citation: Lanza, L.G.; Cauteruccio, A. Precipitation Measurement

Instruments: Calibration, Accuracy and Performance. Water 2022, 14, 811. https://doi.org/10.3390/w14050811

Received: 31 January 2022

Accepted: 10 February 2022

Published: 4 March 2022

Publisher's Note: MDPI stays neutral with regard to jurisdictional claims in published maps and institutional affiliations.

Copyright: () 2022 by the authors Licensee MDPI, Basel, Switzerland. This article is an open access article distributed under the terms and conditions of the Creative Commons Attribution (CC BY) license (https:/ / creativecommons.org/licenses/by/ $4.0 /)$.
Though ranking high among the relevant environmental variables (due to the wellknown significant interactions with the everyday human life and economic activities), atmospheric precipitation is not yet measured operationally with neither the degree of accuracy that would meet the most demanding applications nor any rigorous standardization framework [1,2]. Precipitation records are indeed collected in various countries using different approaches to the treatment of the measurement accuracy and uncertainty issues. This inevitably introduces drastic limitations to the comparability and usability of measurements taken in various parts of the world, in both scientific studies and technical applications, not to mention the difficulties to achieve a reasonably accurate characterization of the planetary water cycle. Not only in-situ measurements (often termed the "ground

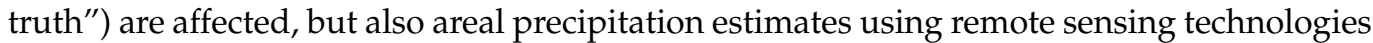
suffer from the lack of suitable calibration and validation, obtained by comparison with accurate direct measurements at the ground.

Calibration details for any specific instrument employed and the assessment of the residual measurement uncertainty remain unreported in most cases, and totally concealed to the user of the derived precipitation dataset. To overcome the above limitations and based on the experimental activities performed within international intercomparison campaigns (see, e.g., [3]), some normative effort has been recently finalized at the European scale with the publication of the first international standard on the accuracy of catchingtype precipitation measurement instruments (EN 17277:2019 [4]), but the development of a similar norm at the global scale (ISO, WMO) is still lagging. Enlarging the coverage of such standards to include the non-catching family of precipitation gauges would also be desirable.

The research community is active in this field by providing theoretical and experimental contributions, focusing on the quality of precipitation measurements taken with various instruments and on the propagation of the possible inaccuracies into the modelling of hydro-meteorological processes. The aim of the present Special Issue on "Precipitation Measurement Instruments: Calibration, Accuracy and Performance" was to collect contributions about the investigation of the main sources of error in liquid (rain) and solid (snow) precipitation measurements and their impact on the scientific research and applications. The six published papers span over various related topics and provide a few insights on specific aspects of the overall issue, as synthesized below.

Huang [5] focuses on the precipitation process in the atmosphere, more specifically in the stratiform clouds with embedded convective cells, as observed through the cloud imaging probe-an airborne instrument able to capture the microphysical structure of cloud systems. The work addresses errors introduced by the shattering of cloud particles into many fragments when impacting on the probe's arms or tips or interacting with the turbulence and wind shear generated by the probe housing. These errors result in artificially high concentrations of small ice particles being detected by the probe with 
possible artifacts on the measured size distribution function, bulk microphysical and scattering properties. A time-variant interarrival time threshold method is proposed by the author to identify the particle shattering events, using data from the Beijing Cloud Experiment. The author concludes that shattered fragments may increase the measured particle number concentration by up to one or two orders of magnitude, and that their influence in a convective region is nearly three times that in a stratiform cloud region. The overestimation of the ice water content due to the shattering in a convective region is about $20 \%$ higher than in a stratiform cloud region. This work contributes to assess the uncertainty of measurements in two different cloud environments, and to understand possible defects of the historical data in cloud microphysics research and numerical model development.

This paper exemplifies one of the common issues due to the interaction of the measurement instrument with the measurand, typical of probes that are immersed in the physical process they are intended to sample. Similar to most in-situ precipitation measurement instruments, the presence of the external body of the probe causes some modification of the characteristics of the measurand in the vicinity of the probe, and therefore within the sensing volume. Such sources of error are usually quite systematic (though an associated residual uncertainty may be present) and can be quantified to adjust the measurement, which may not be trivial at all. At least the user should be made aware of the issue and of the potential impact of such sources of environmental errors on the measurement accuracy. The paper by Huang [5] is a step ahead in this direction since the relative impact of the shattering is quantified for two common types of cloud systems prone to produce precipitation at the ground surface.

Further addressing the issue of the interaction of the measurement instrument with the surrounding environment, the contribution by Cauteruccio et al. [6] focuses on the impact of wind and turbulence on in-situ snow measurements using catching type gauges. This is an Editor's Choice article, based on recommendations by the scientific editors of MDPI journals from around the world (editors select a small number of articles recently published in the journal that they believe will be particularly interesting to authors, or important in this field). Suitable values of the turbulence intensity as observed in the field at the height of a typical snow gauge are imposed to the incoming airflow in the numerical simulation of the wind-induced bias of snowfall measurements, differently from literature approaches where steady and uniform free-stream conditions are assumed. Using Large Eddy Simulations and a Lagrangian particle tracking model, catch ratios for dry snow particles are obtained and the collection efficiency is calculated based on a suitable particle size distribution. The paper shows that in turbulent conditions a stronger undercatch is obtained at the investigated wind velocity and snowfall intensity below $10 \mathrm{~mm} \mathrm{~h}^{-1}$.

Wind is indeed the major environmental source of measurement biases for in-situ precipitation measurements, resulting in a lower amount of collected precipitation than what is expected in undisturbed (still air) conditions. Adjustment curves are necessary to elaborate the raw measurements and correct for this well-known bias. Different from a previous work [7], where the free-stream turbulence effect was investigated using a time-invariant approach and results provided in terms of the attenuation of the airflow updraft and acceleration above the collector of the gauge, in this case the particle-fluid interaction was also addressed (using a one-way coupled model), and the uniform and turbulent free-stream conditions were compared in terms of catch ratios and collection efficiency. The result of this study demonstrates that adjustment curves based on the simplifying assumption of uniform free-stream conditions do not accurately portray the wind-induced bias of snow measurements.

A second paper on the collection efficiency of catching type gauges by Cauteruccio and Lanza [8] is included in this Special Issue to also cover liquid (rain) further than solid (snow) precipitation measurements. It is evident that snow is more sensitive than rain to the wind-induced deviations, although errors in rain measurements are relevant as well, especially under light to moderate rainfall intensity. This paper moves from the observation that adjustments based on experimental collection efficiency curves are rarely 
applied operationally to rain records obtained from catching-type rain gauges, due to their strict dependence on the site where the test field is geographically located, the associated precipitation and wind climatology, and on the reliability and accuracy of the assumed reference gauge. By exploiting the potential of numerically solving the basic equations of fluid motion and of particle-fluid interactions, a cylindrical gauge having the shape of the most widely used catching type precipitation gauges is approached to derive easy-to-use adjustment curves as a function of the measured rainfall intensity and wind speed.

The functional dependency of the collection efficiency on rainfall intensity is demonstrated in this work and the results confirm that such a parameterization holds for liquid precipitation measurements. Using rainfall intensity as a controlling factor for the collection efficiency has sound physical bases in the relationship between rainfall intensity and the particle size distribution, and its role can only be quantified using numerical simulations of both the airflow field and the particle motion. Wind velocity is the only ancillary variable required to perform the adjustment and, since wind is often measured by operational weather stations together with the precipitation intensity, its use adds no relevant burden to the cost of meteo-hydrological networks.

The paper by Song et al. [9] introduces the analysis of the impact of different measurement sources on the results of hydrological modelling of daily and monthly streamflow at the basin scale. The authors explain that the accuracy of gauged station data is in general the highest, but the distribution of such stations is often uneven, which makes it impossible to accurately measure the spatial variations in precipitation. Areal estimates from two satellitebased precipitation products (Tropical Rainfall Measurement Mission, TRMM; Integrated Multi-satellite Retrievals for GPM, IMERG) and one reanalysis precipitation product (China Meteorological Assimilation Driving Datasets for the Soil and Water Assessment Tool (SWAT) model, CMADS) are studied to compare their streamflow simulation performance in the Qujiang River Basin, China (with a total area of about 38,900 $\mathrm{km}^{2}$ ). Results indicate that CMADS + SWAT and IMERG + SWAT can basically meet the needs of streamflow simulations in the basin, except for extreme streamflow simulation at a daily scale.

It is well-known that the basin response has an aggregation effect on the precipitation occurring over the different portions of the basin surface area, therefore some inaccuracies would be averaged out while others would sum up and increase the overall bias of the result. Indeed, the worst results are obtained in case of high intensity events, where the role of biases in rainfall measurements is the largest also for ground-based instruments. Assessing the accuracy of the original rain gauge measurements used in the production of the compared areal products is not among the objectives of this paper, and in general it is not easy to single out the performance of remote sensing instruments in producing areal estimates from those of the single gauges used for calibration. However, the relevance of the measurement inaccuracies is clearly demonstrated, especially when important features such as extreme precipitation and runoff conditions are simulated.

The contribution by Caloiero et al. [10] addresses the role of the accuracy of precipitation measurement instruments in the statistical analysis of trends in liquid precipitation in the Calabria region of Italy. The available monthly precipitation dataset is collected since 1916 by the Multi-Risk Functional Centre of the Regional Agency for Environment Protection from more than 100 stations-out of which 79 are used in this study, and rainfall series are tested for homogeneity and possible trends. More than 50\% of monthly rainfall series are found to be homogeneous, although 35 out of 79 series are homogenized by correcting a total of 46 breaks and an average of 1.3 breaks per homogenized series. Statistical tests are applied to assess the presence of trends and their significance in the monthly, seasonal, and annual rainfall series. Negative trends appear at the monthly scale in January and December, while an opposite behavior is evident in July and especially in September, when almost the entire region presents a positive trend.

Caloiero et al. [10] note that high quality long-term time series are essential for climate studies, since, e.g., climate trend analyses are not imaginable without a clear understanding of the homogeneity of data to avoid that the actual climate signal in original series is 
concealed behind non-climatic factors, whose magnitude can be larger than the climate variation signals. This is an important issue, often understated in climate studies, where the accuracy of the basic data sets is rarely addressed to a sufficient extent. For typical tipping-bucket rain gauges, the results of this work complement the long-lasting awareness (see, e.g., [11]) that any typical monitoring network that is continuously updated with more reliable gauges would experience an artificial climatic trend towards increasing climatological precipitation in case mechanical errors affecting historical records are systematically neglected.

As a third example of the impact of measurement accuracy on the hydrological applications, Wijayarathne et al. [12] contribute a study of radar-gauge merging techniques for use in operational flood forecasting in urban watersheds. Indeed, after adjusting radar estimates with gauge observations by combining their advantages while minimizing their weaknesses, the authors manage to increase their accuracy and reliability. The authors use various techniques to merge precipitation estimates from two dual-polarized C-band King City radars and two next-generation S-band radars with rain gauge data for the Humber River watershed (semi-urban, $911 \mathrm{~km}^{2}$ ) and the Don River watershed (urban, $350 \mathrm{~km}^{2}$ ) in Ontario, Canada, and to assess their relative performance against an independent gauge network at the hourly scale. All the methods perform better for low- to medium-intensity precipitation but deteriorate for intense events, while they always outperform estimates based on the radar only (with a better agreement in the summer events).

This study emphasizes that the radar estimates largely benefit from radar-gauge merging techniques, therefore reducing the bias of precipitation products based on radar only and improving the accuracy of flood event simulation and forecasting in urban areas. At the scale of urban hydrology applications, the role of measurement biases is particularly important since the high-intensity/short-duration events producing the most relevant urban floods are also the most affected by instrumental sources of error. This is confirmed in the paper by Wijayarathne et al. [12], where the performance of all methods used are shown to deteriorate with increasing the severity of rainfall events.

Overall, the six papers included in this Special Issue span over the most relevant aspects of the proposed topic. From the strictly instrumental side, they range from the accuracy assessment of cloud particles in the atmosphere to the impact of atmospheric conditions at the ground (wind velocity and free-stream turbulence) on in-situ precipitation measurements. Then, the impact of the measurement quality on the applications is investigated, first on the hydrological modelling at the large basin scale, then on the statistical analysis of trends in historical series, and finally on the hydrological modelling at the urban scale.

This conceptual chain, starting from the quantification of measurement biases and aiming at the analysis of the propagation of such biases through the hydrologic applications, is also the backbone of the research project "Reconciling precipitation with runoff: the role of understated measurement biases in the modelling of hydrological processes", funded by the Italian MIUR (Ministry of Education, Universities and Research), grant number PRIN20154WX5NA, under which some of the presented research was developed.

The present collection provides a significant overview of the many aspects involved while also focusing on specific research issues, still debated and unresolved in the geoscience community. The individual studies presented in each paper contributed to the advancement of knowledge in their specific field and constitute a good documental reference for both researchers and practitioners.

Author Contributions: Conceptualization, L.G.L. and A.C.; writing-original draft preparation, L.G.L. and A.C.; writing-review and editing, L.G.L. and A.C.; funding acquisition, L.G.L. All authors have read and agreed to the published version of the manuscript.

Funding: This research was funded by the Italian MIUR (Ministry of Education, Universities and Research), grant number PRIN20154WX5NA, project "Reconciling precipitation with runoff: the role of understated measurement biases in the modelling of hydrological processes". 
Conflicts of Interest: The authors declare no conflict of interest.

\section{References}

1. Lanza, L.G.; Cauteruccio, A. Accuracy assessment and intercomparison of precipitation measurement instruments. In Precipitation Science; Michaelides, S., Ed.; Elsevier: Amsterdam, The Netherlands, 2021; pp. 3-35. [CrossRef]

2. Lanza, L.G.; Cauteruccio, A.; Stagnaro, M. Rain Gauge Measurements. In Rainfall. Modeling, Measurement and Applications; Morbidelli, R., Ed.; Elsevier: Amsterdam, The Netherlands, 2022; pp. 77-108. [CrossRef]

3. Lanza, L.G.; Vuerich, E.; Gnecco, I. Analysis of highly accurate rain intensity measurements from a field test site. Adv. Geosci. 2010, 25, 37-44. [CrossRef]

4. EN 17277:2019; Hydrometry-Measurement Requirements and Classification of Rainfall Intensity Measuring Instruments. European Committee for Standardization: Brussels, Belgium, 2019.

5. Huang, M. Differences in the Ice Particle Shattering Impact on the CIP Measurements in the Stratiform Cloud Region and the Embedded Convection Region. Water 2021, 13, 2322. [CrossRef]

6. Cauteruccio, A.; Colli, M.; Lanza, L.G. On Neglecting Free-Stream Turbulence in Numerical Simulation of the Wind-Induced Bias of Snow Gauges. Water 2021, 13, 363. [CrossRef]

7. Cauteruccio, A.; Colli, M.; Freda, A.; Stagnaro, M.; Lanza, L.G. The role of free-stream turbulence in attenuating the wind updraft above the collector of precipitation gauges. J. Atmos. Ocean. Technol. 2020, 37, 103-113. [CrossRef]

8. Cauteruccio, A.; Lanza, L.G. Parameterization of the Collection Efficiency of a Cylindrical Catching-Type Rain Gauge Based on Rainfall Intensity. Water 2020, 12, 3431. [CrossRef]

9. Song, Y.; Zhang, J.; Meng, X.; Zhou, Y.; Lai, Y.; Cao, Y. Comparison Study of Multiple Precipitation Forcing Data on Hydrological Modeling and Projection in the Qujiang River Basin. Water 2020, 12, 2626. [CrossRef]

10. Caloiero, T.; Filice, E.; Coscarelli, R.; Pellicone, G. A Homogeneous Dataset for Rainfall Trend Analysis in the Calabria Region (Southern Italy). Water 2020, 12, 2541. [CrossRef]

11. La Barbera, P.; Lanza, L.G.; Stagi, L. Tipping-bucket mechanical errors and their influence on rainfall statistics and extremes. Water Sci. Technol. 2002, 45, 1-9. [CrossRef]

12. Wijayarathne, D.; Coulibaly, P.; Boodoo, S.; Sills, D. Evaluation of Radar-Gauge Merging Techniques to Be Used in Operational Flood Forecasting in Urban Watersheds. Water 2020, 12, 1494. [CrossRef] 